\title{
The age of onset of substance use is related to the coping strategies to deal with treatment in men with substance use disorder
}

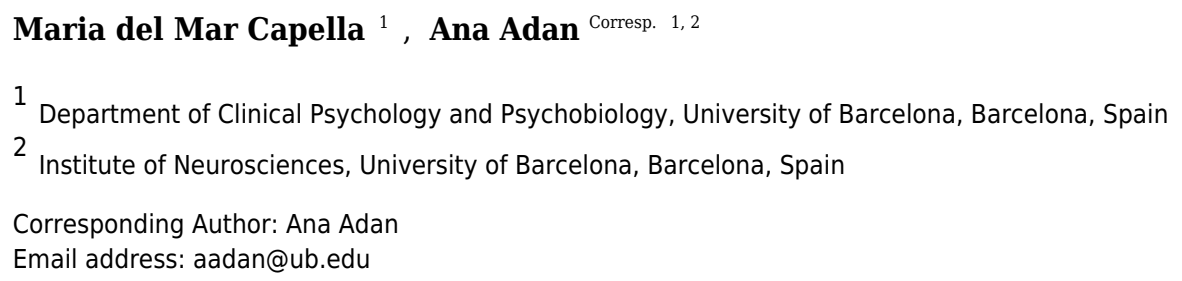

Background. The age of onset of substance use (OSU) as well as the coping strategies (CS) influence both the development and the course of Substance Use Disorders (SUD). We aim to examine the differences in the CS applied to deal with treatment in men with SUD, considering whether the age of OSU had begun at age 16 or earlier (OSU $\leq 16)$ or at 17 years or later $(O S U \geq 17)$, as well as the associations of the CS with clinical variables were studied. Methods. A total of 122 patients with at least 3 months of abstinence, 60 with $\mathrm{OSU} \leq 16$ and 62 with $\mathrm{OSU} \geq 17$, were evaluated through the Coping Strategies Inventory and clinical assessment tools. Results. The OSU $\leq 16$ patients were younger and presented a worse clinical state. Compared to the norms, the SUD patients were less likely to use adaptive CS, although this was more remarkable for the $\mathrm{OSU} \leq 16$ group. Furthermore, the OSU $\leq 16$ patients presented a CS pattern of higher Disengagement, with lesser use of Social Support and higher Problem Avoidance and Social Withdrawal. In the whole SUD sample, the severity of addiction, number of relapses and age of OSU (as a continuous variable) were related to maladaptive coping. Nevertheless, the cut-off age of OSU modulated these results. Conclusions. The $0 S U \leq 16$ was a risk factor for presenting greater clinical severity and a more dysfunctional CS profile to deal with treatment. Thus, the cut-off age considered has allowed us to differentiate SUD patients with more vulnerability to present worse clinical prognosis who may require specific prevention and rehabilitation strategies discussed throughout this work. 
1 The Age of Onset of Substance Use Is Related to the Coping Strategies to Deal 2 with Treatment in Men with Substance Use Disorder

3

4

5

6

7 Spain $8{ }^{2}$ Institute of Neurosciences, University of Barcelona, Barcelona, Spain 9
Corresponding author:

Ana Adan, aadan@ub.edu
Maria del Mar Capella ${ }^{1} \&$ Ana Adan ${ }^{1,2}$

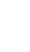

14

$(16$

7

8

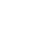

1

2

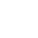

24

6

7

0

${ }^{1}$ Department of Clinical Psychology and Psychobiology, University of Barcelona, Barcelona, 
41

42

43

44

45

46

47

48

49

50

51

52

53

54

55

56

57

58

59

60

61

62

63

64

65

66

67

68

69

70

71

72

73

74

75

76

77

78

79

80

81

\section{ABSTRACT}

Background. The age of onset of substance use (OSU) as well as the coping strategies (CS) influence both the development and the course of Substance Use Disorders (SUD). We aim to examine the differences in the CS applied to deal with treatment in men with SUD, considering whether the age of OSU had begun at age 16 or earlier $(\mathrm{OSU} \leq 16)$ or at 17 years or later ( $\mathrm{OSU} \geq 17$ ), as well as the associations of the CS with clinical variables were studied. Methods. A total of 122 patients with at least 3 months of abstinence, 60 with OSU $\leq 16$ and 62 with $\mathrm{OSU} \geq 17$, were evaluated through the Coping Strategies Inventory and clinical assessment tools. Results. The OSU $\leq 16$ patients were younger and presented a worse clinical state. Compared to the norms, the SUD patients were less likely to use adaptive CS, although this was more remarkable for the OSU $\leq 16$ group. Furthermore, the OSU $\leq 16$ patients presented a CS pattern of higher Disengagement, with lesser use of Social Support and higher Problem Avoidance and Social Withdrawal. In the whole SUD sample, the severity of addiction, number of relapses and age of OSU (as a continuous variable) were related to maladaptive coping. Nevertheless, the cutoff age of OSU modulated these results.

Conclusions. The OSU $\leq 16$ was a risk factor for presenting greater clinical severity and a more dysfunctional CS profile to deal with treatment. Thus, the cut-off age considered has allowed us to differentiate SUD patients with more vulnerability to present worse clinical prognosis who may require specific prevention and rehabilitation strategies discussed throughout this work.

\section{INTRODUCTION}

Substance Use Disorders (SUD) are considered a public health issue since they have severe personal and community consequences, as well as a high worldwide prevalence (United Nations Office on Drugs and Crime [UNODC], 2015). Despite welfare programs, patients have a high variability of response to interventions (Kampman et al., 2007) and high rates of relapse (Suijkerbuijk et al., 2015; Witkiewitz \& Marlatt, 2004). Moreover, the age of onset of substance use (OSU) usually occurs at very early ages and it has been established as a strong predictor to future SUD (Woodcock, Lundahl \& Stoltman, 2015) and linked both to worse clinical course and cognitive functioning (Capella, Benaiges \& Adan, 2015; Eddie, Epstein \& Cohn, 2015; Hammond, Mayes \& Potenza, 2014; Kendler et al., 2013) and greater brain alterations (Elofson, Gongvatana \& Carey, 2013). Thus, it is necessary to further study the risk factors and course severity in SUD, such as age of OSU, with the aim of improving prevention and treatment strategies according to their characteristics, to make them more effective.

In this line, we have attempted to clarify the reasons that lead people to consume substances. While the age of OSU is often linked to social goals and to its positive reinforcement, once SUD consumption has developed it is maintained in order to reduce the stress-based negative affect 
82 (Blevins et al., 2014; Dermody, Cheong \& Manuck, 2014). Although there are multiple factors

83

84

85

86

87

88

89

90

91 that influence the clinical prognosis of SUD patients, certain psychological characteristics are essential. Among these, we can mention the coping strategies (CS) used to face adversity since it has been shown that they influence both the development and course of SUD and its treatment outcome (Marquez-Arrico, Benaiges \& Adan, 2015; Walker \& Stephens, 2014).

Lazarus and Folkman (1984) define CS as cognitive and behavioral responses aimed at managing internal or external demands. They have established two major ways of coping: engagement, aimed at dealing with the stressors or their related emotions, and generally considerate adaptive; and disengagement, targeted to avoid the stressful situations or their related emotions, and mainly regarded as maladaptive (Carver \& Connor-Smith, 2010; Skinner et al., 2003; Tobin et al., 1989). People are likely to show a relatively stable disposition towards the habitual use of certain CS to diverse stressors, which to some extent would vary depending on situation-specific variables in a concrete coping episode or stressor (Bauer et al., 2016; Bouchard, Guillemette \& Landry-Léger, 2004; Lazarus \& Folkman, 1984) and age (Mauro et al., 2015; Woodhead et al., 2014).

Substance consumption is considered as a type of coping behavior to avoid stress, focused on emotions and directed to temporarily alleviate the negative affect that certain stressors generate, although in the long term it will trigger more severe problems, such as the need to consume again (Bavojdan, Towhidi \& Rahmati , 2011; Buckner et al., 2015; Hruska et al., 2011). The avoidance-based coping style has been established as a risk factor with a poor prognosis for the initiation and maintenance of SUD. In contrast, problem-focused coping is considered a protective factor against consumption (Blevins et al., 2014; Coriale et al., 2012; Dermody, Cheong \& Manuck, 2014; Marquez-Arrico, Benaiges \& Adan, 2015; Walker \& Stephens, 2014; Woodhead et al., 2014) and is associated to better mental health (Bavojdan, Towhidi \& Rahmati, 2011; Nyamathi et al., 2007). Similarly, social support is a CS with a protective effect against stress (Hyman et al., 2009) and the development of depression (Aarts et al., 2015), having been observed that it correlates negatively with the relapse rate of SUD patients (Chauchard, Septfons \& Chabrol, 2013; Dolan et al., 2013; Hägele et al., 2014). However, recent results are controversial (Nyamathi et al., 2007) and need to be contrasted.

Adolescence is a risk stage for the onset of several psychiatric disorders, such as those related with substance use (Hägele et al., 2014; Kirst et al., 2014). Since early OSU is associated to future SUD development (Woodcock, Lundahl \& Stoltman, 2015) and to more severe characteristics (Capella, Benaiges \& Adan, 2015; Eddie et al., 2015; Hammond, Mayes \& Potenza, 2014; Kendler et al., 2013), studying the CS of addicts and their clinical implications, considering the age of OSU, is a research area of undoubted clinical interest.

Based on characteristics of brain ontogeny (Kunert, Derichs \& Irle, 1996; Lambe, Krimer \& Goldman-Rakic, 2000; Shaw et al., 2006; Sundram, 2006), previous studies have found that patients who begin consumption at age 16 or earlier, when compared to those with onset at age 17 or later, have a lower premorbid intelligence quotient (Capella, Benaiges \& Adan, 2015; Pope et al., 2003), worse neuropsychological performance (Ehrenreich et al., 1999; Jockers-Scherübl et al., 2007) and less cerebral and gray matter volume (Wilson et al., 2000). However, 
123

124

125

126

127

128

129

130

131

132

133

134

135

136

137

138

139

140

141

142

143

144

145

146

147

148

149

150

151

152

153

154

155

156

157

158

159

160

161

162

163

considering this cut-off age, no previous studies have provided data about the possible differences in CS patterns and their relationship with clinical variables.

Our paper has two aims. The first is to assess the differences in the CS profile to deal with the treatment of men diagnosed with SUD, depending on whether they initiated substance use at age 16 or earlier $(\mathrm{OSU} \leq 16)$ or at age 17 or later $(\mathrm{OSU} \geq 17)$, as well as in relation to normative data. The second is to explore the relationships among CS- and SUD-related clinical variables.

\section{METHOD}

\section{Study design and participants}

We enrolled 122 patients under SUD treatment in different healthcare resources (ambulatory drug use treating or residential in therapeutic community) in a cross-sectional study design. All were male, given the high prevalence of this gender in SUD (UNODC, 2015) and to avoid biasing the results due to sex differences (Woodhead et al., 2014). Participants were derived from treatment centers after selection according our inclusion/exclusion criteria. In a first evaluation session we confirmed the diagnosis by a researcher (trained clinical psychology postgraduate) responsible of clinical assessment. In a second session, the coping strategies assessment tool along with other tests not presented in this manuscript were administered. After collecting data, they were assigned to two groups according to age of OSU: one for OSU at age 16 or earlier (OSU $\leq 16 ; n=60)$, and one for OSU at age 17 or later $(\mathrm{OSU} \geq 17 ; n=62)$. The consideration of this age cut-off was based on the neurodevelopmental characteristics (Kunert, Derichs \& Irle, 1996; Lambe, Krimer \& Goldman-Rakic, 2000; Shaw et al., 2006; Sundram, 2006), as well as the differences in cognitive performance found in previous studies (Capella, Benaiges \& Adan, 2015; Ehrenreich et al., 1999; Jockers-Scherübl et al., 2007; Pope et al., 2003).

The inclusion criteria were: (1) current or past diagnosis of SUD confirmed by a diagnostic interview according to the criteria in the Diagnostic and Statistical Manual of Mental Disorders, Fourth Edition Text Revised (DSM-IV-TR; American Psychiatric Association, 2000); (2) with abstinence for at least 3 months at the time of the study (excluding caffeine or nicotine consumption), confirmed by urinalysis, to ensure the overcoming of withdrawal symptoms and minimum adherence to treatment; (3) age between 18-55 years. The exclusion criteria were: (1) presence of mental retardation or pervasive developmental disorder, history of traumatic brain injury, neurological injury or any other medical problem which could interfere in the assessment; (2) presence of a comorbid axis I mental disorder, such mood or affective disorders, confirmed by a diagnostic interview according to DSM-IV-TR criteria.

All patients provided written informed consent and were not compensated for their participation. The ethic committee of the University of Barcelona approved this study (IRB00003099), which meets the ethical principles of the declaration of Helsinki (World Medical Association, 2013). This study was part of a larger project on clinical characteristics, neuropsychological functioning, personality traits and circadian rhythmicity in SUD and Dual Diagnosis patients. 


\section{Clinical and sociodemographic measures}

Through a structured interview designed specifically for our study and the Structural Clinical Interview for the DSM-IV Axis I Disorders (SCID-I; First et al., 1999), we collected sociodemographic (age, marital, educational and economic status) and clinical data (presence of psychiatric pathology and substance use family history, suicidal attempts, past treatment for SUD, consumption pattern, type of drugs used, age of OSU, duration of drug use, residential or ambulatory treatment, medication, abstinence periods and relapses). This information was confirmed with the medical history of the centers' databases and with the patients' treating psychiatrist.

The Clinical Global Impression questionnaire (CGI; Guy, 1976) was administered as a subjective measure of clinical severity. Furthermore, severity of SUD was assessed using the Drug Abuse Screening Test (DAST-20; Skinner \& Goldberg, 1986) through its Spanish version (Gálvez \& Fernández, 2010), which provides a total score from 0 to 20 (0 no addiction, 1-5 low, 6-10 intermediate, 11-15 substantial, and 16-20 severe).

\section{Coping strategies assessment}

CS were assessed by means of the Spanish version (Cano-García, Rodríguez-Franco \& Martínez, 2007) of the Coping Strategies Inventory (CSI; Tobin et al., 1989). Patients assessed the frequency with which they had used the strategies described to deal with their SUD treatment. The CSI is composed by 41 items with 5-point Likert scale answers, of which 40 configure the primary scales with one additional item on self-perceived coping ability. The CSI has a hierarchical structure composed by eight primary, four secondary and two tertiary scales. The primary scales are: Problem Solving, Cognitive Restructuring, Social Support, Express Emotions, Problem Avoidance, Wishful Thinking, Social Withdrawal, and Self-Criticism. The secondary scales are: Problem Focused Engagement (composed by Problem Solving and Cognitive Restructuring), Emotion Focused Engagement (Social Support and Express Emotions), Problem Focused Disengagement (Problem Avoidance and Wishful Thinking) and Emotion Focused Disengagement (Social Withdrawal and Self Criticism). The tertiary scales of the CSI are Engagement (Problem and Emotion Focused Engagement) and Disengagement (Problem and Emotion Focused Disengagement).

\section{Statistical analyses}

Descriptive statistics and frequencies were calculated to describe the total study sample. Differences in sociodemographic and clinical variables between groups were explored with the Mann-Whitney U test $(U)$ or with the Chi Square test $\left(\chi^{2}\right)$ for categorical variables. The Student's t-test $(t)$ was used when the quantitative data fulfilled the necessary conditions, and the $U$ test was used instead when those conditions were not met. Factorial analysis of eight factors for CSI was performed with a normalized varimax rotation employed to achieve factor simplicity. Furthermore, internal consistency for the primary scales was calculated with the Cronbach's alpha coefficients. Three multivariate analyses of covariance (MANCOVA) were performed 
205

206

207

208

209

210

211

212

213

214

215

216

217

218

219

220

221

222

223

224

225

226

227

228

229

230

231

232

233

234

235

236

237

238

239

240

241

242

243

244

245

considering the primary, secondary and tertiary CSI scales. Age was considered as covariate, since it could be a confounding factor (Mauro et al., 2015; Woodhead et al., 2014). An additional analysis was carried out considering the treatment regimen (residential or ambulatory), to assess whether this was an indicator of differences in the CS profile to deal with treatment related to the recruitment of patients and not related to the age of OSU. The Bonferroni test was applied in all analyses to reduce the occurrence of a type I error. The effect size was calculated with the partial Eta squared $\left(\eta_{p}^{2}\right)$, assuming a value of 0.01 as low, of 0.04 as moderate and of 0.1 as high (Huberty, 2002). The data were compared to the Spanish norms, only available for the primary scales (Cano-García, Rodríguez-Franco \& Martínez, 2007), using percentiles.

The relationships between CS and SUD clinical variables were studied in two steps, both for the total sample and for each group. First, we carried out correlational analyses between CS and clinical data; then, the significant results were introduced in a multiple stepwise regression analyses with CS as dependent variables.

Data were analyzed using the Statistical Package for the Social Sciences (SPSS; version 15.0), considering bilateral statistical significance with an established type I error at $5 \%(p<.05)$.

\section{RESULTS}

\section{Differences in sociodemographic and clinical data}

The total sample was aged 20 to $55(M=35.97, S D=8.31)$ and most of the patients had completed the Spanish compulsory education (from 6 to 16 years). Regarding sociodemographic variables, the only observed difference between groups was the lower mean age of the OSU $\leq 16$ group $(p<.001)$, while both groups did not differ in years of education, marital and economic status. The analyses of the clinical variables provided no significant differences between groups regarding relatives with other psychiatric disorders than SUD and number of suicidal attempts. Instead, in the OSU $\leq 16$ group it was more frequent to have relatives with $\operatorname{SUD}(p=.025)$. See Table 1.

\section{Insert Table 1}

With respect to SUD data, the OSU $\leq 16$ group had higher rates of polyconsumption $(p=.030)$, and patients in residential rather than ambulatory treatment $(p=.013)$, lower age of OSU $(p<$ $.001)$ and longer duration of drug use $(p=.016)$. Furthermore, the groups showed differences in the type of substances used. In the OSU $\leq 16$ group, there were higher rates of cannabis ( $p<$ $.001)$, and hallucinogens consumption $(p=.042)$, while in the OSU $\geq 17$ group there are higher rates of cocaine consumption $(p=.046)$. In the overall sample, as well as in both groups, the substances more frequently used were cocaine, alcohol and cannabis. No differences between groups were found in the other SUD clinical characteristics studied (see Table 2).

\section{Insert Table 2}

\section{Coping Strategies Inventory comparisons}


247 The eight factors obtained from factorial analysis of the CSI explained the $61.95 \%$ of variance

$248(F 1=9.73, F 2=9.55, F 3=8.61 ; F 4=8.35 ; F 5=7.93 ; F 6=7.16, F 7=5.34$ and $F 8=5.29)$.

249 The set of items of the Problem Solving and Wishful Thinking scales are the most clearly

250 associated with one single factor, with loadings superior to .43. Regarding the scales of Self-

251 Criticism, Express Emotions and Cognitive Restructuring scales, only four of the five items

252 selected converge in the factors, with values higher to .44. Finally, Social Support, Problem

253 Avoidance and Social Withdrawal are the scales that correspond less to the items of the originals.

254 Cronbach's alpha coefficients of internal consistency for the primary scales were all adequate

255 for the total sample studied: Problem Solving (0.79), Cognitive Restructuring (0.71), Social

256 Support (0.72), Express Emotions (0.76), Problem Avoidance (0.70), Wishful Thinking (0.77),

257 Social Withdrawal (0.74) and Self-Criticism (0.77).

258 The comparisons among percentile scores in the CSI primary scales according to the Spanish

259 normative data (see Figure 1) showed lower scores in the overall sample $(<40$ percentile) in

260 Problem Solving, and higher scores ( $>60$ percentile) in Express Emotions, Wishful Thinking,

261 Social Withdrawal and Self-Criticism. When considering groups, higher scores in Wishful

262 Thinking, Social Withdrawal and Self-Criticism were observed in both. On the other hand, the

263 OSU $\geq 17$ group had higher scores in Social Support and lower scores in Problem Avoidance.

264

265

266

267

268

269

270

271

272

273

274

275

276

277

278

279

280

281

282

283

284

285

\section{Insert Figure 1}

The MANCOVA analyses showed several significant differences between groups for the CSI scales (see Table 3). Results in the primary scales indicated that the OSU $\leq 16$ group had lower scores in Social Support ( $p=.019)$, and higher scores both in Problem Avoidance $(p=.037)$, and in Social Withdrawal $(p=.049)$. No differences between groups were found in the other primary and secondary scales. Regarding tertiary scales, the groups were similar in their use of Disengagement strategies, but the $\mathrm{OSU} \leq 16$ group showed lower scores in Engagement strategies $(p=.038)$.

\section{Insert Table 3}

In the additional analysis carried out considering the treatment regimen (residential or ambulatory) as a group variable. No significant differences between groups were found regarding any primary, secondary or tertiary CSI scales ( $p>.241$; in all cases), neither considering age and age of OSU as covariates ( $p>.240$; in all cases).

\section{Relations among SUD, clinical characteristics and coping strategies}

First, correlations between CS and clinical data, and between CS and SUD clinical characteristics, indicated that only age of OSU (considered as a continuous variable), duration of drug use, number of relapses and DAST-20 were associated with some of the CS: Wishful 
286

287

288

289

290

291

292

293

294

295

296

297

298

299

300

301

302

303

304

305

306

307

308

309

310

311

312

313

314

315

316

317

318

319

320

321

322

323

324

325

326

Thinking, Social Withdrawal, Problem Focused Disengagement, Emotion Focused Disengagement and Disengagement.

Second, the above variables were introduced in regression analyses with the different CS as dependent variables (see Table 4). In the total sample, the DAST-20 explained $11 \%$ of the variance of Problem Focused Disengagement $(p=.002), 13 \%$ of Social Withdrawal $(p=.001)$, $17 \%$ of Wishful Thinking $(p<.001)$ and, together with age of OSU and number of relapses, 23\% of the variance of Emotion Focused Disengagement $(p<.001)$. Age of OSU and number of relapses accounted for $15 \%$ of the variance of Disengagement $(p=.002)$.

Considering the OSU $\leq 16$ group, the regression analysis indicated that the model was significant in only four of the CS. The DAST-20 explained $18 \%$ of the variance of Wishful Thinking $(p=.003)$. The DAST-20 and the number of relapses were significant for Social Withdrawal $(p=.001)$ and Emotion Focused Disengagement $(p=.004)$, explaining 27\% and $22 \%$ of the variance, respectively. Number of relapses explained $12 \%$ of the variance of Disengagement $(p=.018)$.

Moreover, only four significant regression models were observed in the OSU $\geq 17$ group. In this case, the DAST-20 were significant for Wishful Thinking $(p=.022)$, Social Withdrawal $(p=$ $.037)$, Problem Focused Disengagement $(p=.010)$ and Emotion Focused Disengagement ( $p=$ .031 ), accounting for $11 \%, 12 \%, 13 \%$ and $17 \%$ of the variance, respectively.

Insert Table 4

\section{DISCUSSION}

To our knowledge, this is the first study that aims to elucidate the possible existence of differences in CS related to treatment in men with SUD, depending on whether their substance use began at age 16 or earlier, or at age 17 or later. In addition, we have also assessed the influence of clinical variables related to the SUD regarding the CS pattern.

\section{Sociodemographic and clinical differences between groups}

In relation to the sociodemographic data, both groups differ only in age, the patients in the OSU $\leq 16$ group being the youngest. We decided to control the possible effect of this variable on the coping results, given that with the passing of years people may develop some variation in the CS they use (Mauro et al., 2015; Woodhead et al., 2014). The substances more frequently consumed in both groups were cocaine, alcohol and cannabis. However, the patients in the $\mathrm{OSU} \leq 16$ group had a higher frequency of cannabis and hallucinogens consumption, whereas cocaine was the most frequently consumed drug in the $O S U \geq 17$ group. These differences may reflect the social preference for a certain substance at the time the patients were developing their SUD (European Monitoring Centre for Drugs and Drug Addiction, 2016).

When the cut-off age of OSU was considered, the clinical characteristics of both groups fall in line with the only data currently available (Capella, Benaiges \& Adan, 2015), that is, the OSU $\leq 16$ patients present a more severe clinical and SUD pattern, characterized by more substance consumption, greater duration of drug use and the need for a more intensive treatment 
327

328

329

330

331

332

333

334

335

336

337

338

339

340

341

342

343

344

345

346

347

348

349

350

351

352

353

354

355

356

357

358

359

360

361

362

363

364

365

366

367

(residential instead of ambulatory) to achieve abstinence. Other works have analyzed the age of OSU, although without establishing a cut-off point, and have obtained similar results (Eddie, Epstein \& Cohn, 2015; Hammond, Mayes \& Potenza, 2014; Kendler et al., 2013). Moreover, the higher presence of a family history of SUD in the OSU $\leq 16$ group supports the findings on the genetic predisposition and early environmental exposures that precede the onset of drug use in early consumers (Hägele et al., 2014; Hammond, Mayes \& Potenza, 2014). These data should be further explored in future research taking into account the possible mediation of the main substance consumed, since this family factor has not yet been found in cannabis consumers (Pope et al., 2003). Finally, it is interesting to note that the CS profile of the patients was independent of the type of treatment regimen in agreement with a previous study (Adan, Antúnez \& Navarro, 2017).

\section{Coping strategies}

The SUD patients show a tendency to use emotion in order to cope with the stress generated by their treatment. There is a predominance to use maladaptive CS such as avoiding any contact with those persons related to their stressful experience (Social Withdrawal), as well as self-blame for the occurrence of the stressful situation or its improper management (Self-Criticism). When considering the most adaptive pole, the predominant CS is the release of emotions that occur in the process of stress (Express Emotions). When focusing on addressing the problem, the tendency was to do it in an inappropriate way by thinking about non-stressful alternative realities (Wishful Thinking), with a low propensity to active resolution of their difficulties (Problem Solving). This is consistent with the results of previous studies that have found a tendency to maladaptive coping, with lesser use of active coping problem-solving strategies in drug consumers (Marquez-Arrico, Benaiges \& Adan, 2015), which could be at the basis of the onset (Walker \& Stephens 2014; Woodhead et al., 2014) and maintenance of the SUD (Coriale et al., 2012). The pattern described is observed in both groups, although the $O S U \geq 17$ group presents a more adaptive coping profile.

When compared to the $\mathrm{OSU} \geq 17$, the $\mathrm{OSU} \leq 16$ group is characterized by a CS pattern of greater Disengagement (lesser use of Social Support; greater Problem Avoidance and Social Withdrawal). Thus, it seems that the patients with an early OSU present fewer interpersonal skills, showing a tendency to withdraw from their social environment and to avoid contact with other people in order to express their emotions. In this sense, we find that a higher rate of substance and medication use in adults is related to a lesser early childhood social competence (Jones, Greenberg \& Crowley, 2015). Furthermore, in SUD patients under treatment high rates of cooperation (Andó et al., 2012) and stronger social support (Chauchard, Septfons \& Chabrol, 2013; Dolan et al., 2013) have been related to longer abstinence periods, while social withdrawal is higher when the age of OSU is younger (Marquez-Arrico, Benaiges \& Adan, 2015). Moreover, avoidance-based coping has been consistently identified as a moderator of SUD (Bavojdan, Towhidi \& Rahmati, 2011; Hruska et al., 2011), and this could be a key factor in the tensionreduced-based models, where emotional suffering is relieved through avoidance of emotional distress (Buckner et al., 2015). 


\section{Influence on coping strategies of SUD clinical characteristics}

370

371

372

373

374

375

376

377

378

379

380

381

382

383

384

385

386

387

388

389

390

391

392

393

394

395

396

397

398

399

400

401

402

403

404

405

406

407

408

The relations observed among the clinical variables and maladaptive coping are modulated by the age of OSU and, specifically, by the cut-off age studied in this work. In SUD patients, a higher severity of addiction is related to a more dysfunctional coping pattern when they face treatment (higher scores in Wishful Thinking, Social Withdrawal, Problem Focused Disengagement and Emotion Focused Disengagement). Moreover, a higher number of relapses is related to a more frequent use of a coping style based on emotional disengagement (Emotion Focused Disengagement and Disengagement strategies), which is explained by the pattern of the OSU $\leq 16$ group. Thus, those patients with a more severe SUD tend to use maladaptive CS (Blevins et al., 2014; Marquez-Arrico, Benaiges \& Adan, 2015; Nyamathi et al., 2010), and this is related to a higher number of relapses (Chauchard, Septfons \& Chabrol, 2013; Dolan et al., 2013), even the more so as the age of OSU decreases.

There are some limitations in our study that should be mentioned. Almost half of the patients were polyconsumers, which was an impediment to assess separately the effect of each type of substance on CS. However, their possible effect was relatively controlled since the groups had consumed the same main substances (cocaine, alcohol and cannabis). The inclusion of only men in the sample, knowing the influence of gender in CS (Bouchard, Guillemette \& Landry-Léger, 2004; Woodhead et al., 2014), limits the generalization of our results. The wide range of age in the sample may have also contributed to a type-II error. We have analyzed cross-sectional data, which does not allow establishing causal or sequential relations among variables, or if the coping strategies currently used by patients are the same as when they started the substance use or even the treatment. Moreover, the level of perceived stress and affect or mood of participants were not assessed, which could help explain their CS pattern and clinical traits (Aarts et al., 2015; Hyman et al., 2009). While the data obtained in the CSI indicated an adequate internal consistency for the primary scales, the factorial analysis with the eight factor structure model of the Spanish version (Cano-García, Rodríguez-Franco \& Martínez, 2007) was only partially fulfilled, although it is widely agreed and validated. Finally, the low explanatory power obtained in the regression analyses warns us to interpret the results with caution. Future works should include larger patient samples of both men and women, differentiating the main substance consumed, with a longitudinal design that could contribute to clarify the attitudinal or situational character of coping and which variables determine it in order to obtain a better knowledge of its role in later outcomes.

Our results may have clinical interest. We find that SUD patients deal with treatment applying a dysfunctional emotion-based coping style, a style also present at the onset, maintenance and severity of the disorder (Bavojdan, Towhidi \& Rahmati, 2011; Blevins et al., 2014; Buckner et al., 2015; Dermody, Cheong \& Manuck, 2013; Hruska et al., 2011). This suggests that those interventions aimed at developing CS which may prevent consumption, such as problem-focused coping o social support, could be more effective both in addiction prevention and treatment programs. The assessment of cognitive skills seems another key factor to be considered, given that a low neuropsychological performance is related both to the development of SUD in 
409

410

411

412

413

414

415

416

417

418

419

420

421

422

423

424

425

426

427

428

429

430

431

432

433

434

435

436

437

438

439

440

441

442

443

444

445

446

447

448

449

adulthood (Pechtel, Woodman \& Lyons-Ruth, 2012) and to the response to treatment (Kiluk, Nich \& Carroll, 2011). In this regard, it has been shown that, in the rehabilitation of SUD patients, higher cognitive abilities are associated with greater improvement in the quality of the coping skills acquired, which in turn is indirectly associated with treatment benefits. This could be significantly relevant for patients with $O S U \leq 16$, since they present a worse coping style, as shown in the present study, and a lower cognitive performance, as shown in other works (Capella, Benaiges \& Adan, 2015; Ehrenreich et al., 1999; Jockers-Scherübl et al., 2007; Pope et al., 2003). Further research is required to shed light on this issue.

\section{CONCLUSIONS}

A main priority in public health should be to target populations at risk of developing SUD or with a worse clinical prognosis, in order to design more specific intervention programs. In this sense, the cut-off age considered in our study is a contribution, since the OSU $\leq 16$ patients exhibited more vulnerability to present both higher clinical severity and frequency to use of a dysfunctional CS profile to cope with treatment, which were related to the severity of the addiction and relapses. Further studies are needed to explore the possible benefits of improving adaptive coping in these patients for better treatment outcomes, as well as for prevention programs of SUD.

\section{ACKNOWLEDGMENTS}

We thank the Man Project Foundation in Catalonia, the ATRA Association and the Mental Health and Addictions Division of the Mataró Hospital for providing the patients in the sample.

\section{REFERENCES}

Aarts JW, Deckx L, van Abbema DL, Tjan-Heijnen VC, van den Akker M, Buntinx F. 2015. The relation between depression, coping and health locus of control: Differences between older and younger patients, with and without cancer. Psychooncology 24:950-957. DOI: 10.1002/pon.3748

Adan A, Antúnez JM, Navarro JF. 2017. Coping strategies related to treatment in substance use disorder patients with and without comorbid depression. Psychiatry Research 251:325332. DOI: 10.1016/j.psychres.2017.02.035

American Psychiatric Association. 2000. Diagnostic and statistical manual of mental disorders (4th ed. text rev.). Washington, DC: Author.

Andó B, Must A, Kurgyis E, Szkaliczki A, Drótos G, Rózsa S, Szikszay P, Horváth S, Janka Z, Almos PZ. 2012. Personality traits and coping compensate for disadvantageous decisionmaking in long-term alcohol abstinence. Alcohol and Alcoholism 47:18-24. DOI: 10.1093/alcalc/agr144

Bauer MR, Harris LN, Wiley JF, Crespi CM, Krull JL, Weihs KL, Stanton AL. 2016. Dispositional and situational avoidance and approach as predictors of physical symptom bother following breast cancer diagnosis. Annals of Behavioral Medicine 50:370-384. DOI: $10.1007 / \mathrm{s} 12160-015-9763-7$ 
450

451

452

453

454

455

456

457

458

459

460

461

462

463

464

465

466

467

468

469

470

471

472

473

474

475

476

477

478

479

480

481

482

483

484

485

486

487

488

489
Bavojdan MR, Towhidi A, Rahmati A. 2011. The relationship between mental health and general self-efficacy beliefs, coping strategies and locus of control in male drug users. Addiction and Health 3:111-118.

Blevins CE, Stephens RS, Walker DD, Roffman RA. 2014. Situational determinants of use and treatment outcomes in marijuana dependent adults. Addictive Behaviors 39:546-552. DOI: 10.1016/j.addbeh.2013.10.031

Bouchard G, Guillemette A, Landry-Léger N. 2004. Situational and Dispositional Coping: An examination of their relation to personality, cognitive appraisals and psychological distress. European Journal of Personality 18:221-238. DOI: 10.1002/per.512

Buckner JD, Zvolensky MJ, Crosby RC, Wonderlich SA, Ecker AH, Richter A. 2015. Antecedents and consequences of cannabis use among racially diverse cannabis users: An analysis from Ecological Momentary Assessment. Drug and Alcohol Dependence 147:20-25. DOI: 10.1016/j.drugalcdep.2014.12.022

Cano-García FJ, Rodríguez-Franco L, Martínez JG. 2007. Adaptación española del Inventario de Estrategias de afrontamiento. Actas Españolas de Psiquiatría 35: 29-39.

Capella MM, Benaiges I, Adan A. 2015. Neuropsychological performance in polyconsumer men under treatment. Influence of age of onset of substance use. Scientific Reports 5:12038. DOI: $10.1038 /$ srep 12038 .

Carver CS, Connor-Smith J. 2010. Personality and coping. Annual Review of Psychology 61:679704. DOI: 10.1146/annurev.psych.093008.100352

Chauchard E, Septfons A, Chabrol H. 2013. Motivations for cannabis cessation, coping and adaptation strategies, and perceived benefits: Impact on cannabis use relapse and abstinence. Encephale 39:385-392. DOI: 10.1016/j.encep.2013.03.008

Coriale G, Bilotta E, Leone L, Cosimi F, Porrari R, De Rosa F, Ceccanti M. 2012. Avoidance coping strategies, alexithymia and alcohol abuse: a mediation analysis. Addictive Behaviors 37:1124-1129. DOI: 10.1016/j.addbeh.2012.05.018

Dermody SS, Cheong J, Manuck S. 2013. An evaluation of the stress-negative affect model in explaining alcohol use: The role of components of negative affect and coping style. Substance Use and Misuse 48:297-308. DOI: 10.3109/10826084.2012.761713

Dolan SL, Rohsenow DJ, Martin RA, Monti PM. 2013. Urge-specific and lifestyle coping strategies of alcoholics: Relationships of specific strategies to treatment outcome. Drug and Alcohol Dependence 128:8-14. DOI: 10.1016/j.drugalcdep.2012.07.010

Eddie D, Epstein EE, Cohn AM. 2015. Pathways to vulnerability for alcohol problem severity in a treatment-seeking sample. Addictive Disorders and Their Treatment, 14:82-94. DOI: 10.1097/ADT.0000000000000045

Ehrenreic H, Rinn T, Kunert HJ, Moeller MR, Poser W, Schilling L, Gigerenzer G, Hoehe MR. 1999. Specific attentional dysfunction in adults following early start of cannabis use. Psychopharmacology 142:295-301. DOI: 10.1007/s002130050892

Elofson J, Gongvatana W, Carey KB. 2013. Alcohol use and cerebral white matter compromise in adolescence. Addictive Behaviors 38:2295-2305. DOI: 10.1016/j.addbeh.2013.03.001 
490

491

492

493

494

495

496

497

498

499

500

501

502

503

504

505

506

507

508

509

510

511

512

513

514

515

516

517

518

519

520

521

522

523

524

525

526

527

528

European Monitoring Centre for Drugs and Drug Addiction. 2016. European drug report: trends and development. Available at http://www.emcdda.europa.eu/system/files/publications/2637/TDAT16001ENN.pdf/ (accessed 15 January 2017)

First MB, Spitzer RL, Gibbon M, Williams JBW. 1999. Entrevista Clínica Estructurada para los Trastornos del Eje I del DSM-IV, versión clínica (SCID-I). Barcelona: Masson.

Gálvez BP, Fernández LG. 2010. Validación Española del Drug Abuse Screening Test (DAST20 y DAST-10). Health and Addictions 10:35-50.

Guy W. 1976. Early Clinical Drug Evaluation (ECDEU) assessment manual. Rockville: National Institute of Mental Health.

Hägele C, Friedel E, Kienast T, Kiefer F. 2014. How do we 'learn' addiction? Risk factors and mechanisms getting addicted to alcohol. Neuropsychobiology 70:67-76. DOI: 10.1159/000364825

Hammond CJ, Mayes LC, Potenza MN. 2014. Neurobiology of adolescent substance use and addictive behaviors: Prevention and treatment implications. Adolescent Medicine: State of the Art Reviews 25:15-32.

Hruska B, Fallon W, Spoonster E, Sledjeski EM, Delahanty DL. 2011. Alcohol use disorder history moderates the relationship between avoidance coping and posttraumatic stress symptoms. Psychology of Addictive Behaviors 25:405-414. DOI: 10.1037/a0022439

Huberty CJ. 2002. A history of effect sizes indices. Educational and Psychological Measurement 62:227-240. DOI: 10.1177/0013164402062002002

Hyman SM, Hong KA, Chaplin TM, Dabre Z, Comegys AD, Kimmerling A, Sinha R. 2009. A stress-coping profile of opioid dependent individuals entering naltrexone treatment: a comparison with healthy controls. Psychology of Addictive Behaviors, 23:613-619. DOI: $10.1037 / \mathrm{a} 0017324$

Jockers-Scherübl MC, Wolf T, Radzei N, Schlattmann P, Rentzsch J, Gómez-Carrillo A., Kühl KP. 2007. Cannabis induces different cognitive changes in schizophrenic patients and in healthy controls. Progress in Neuro-Psychopharmacology and Biological Psychiatry 31:1054-1063. DOI: 10.1016/j.pnpbp.2007.03.006

Jones DE, Greenberg M, Crowley M. 2015. Early social-emotional functioning and public health: The relationship between kindergarten social competence and future wellness. American Journal of Public Health 105:2283-2290. DOI: 10.2105/AJPH.2015.302630

Kampman KM, Pettinati HM, Lynch KG, Whittingham T, Macfadden W, Dackis C, Tirado C, Oslin DW, Sparkman T, O’Brien CP. 2007. A double-blind, placebo-controlled pilot trial of quetiapine for the treatment of Type A and Type B alcoholism. Journal of Clinical Psychopharmacology 27:344-351. DOI: 10.1097/JCP.0b013e3180ca86e5

Kendler KS, Ohlsson H, Sundquist K, Sundquist J. 2013. A latent class analysis of drug abuse in a national Swedish sample. Psychological Medicine 43:2169-2178. DOI: $10.1017 / \mathrm{S} 0033291713000081$ 
529

530

531

532

533

534

535

536

537

538

539

540

541

542

543

544

545

546

547

548

549

550

551

552

553

554

555

556

557

558

559

560

561

562

563

564

565

566

567

Kiluk B, Nich C, Carroll K. 2011. Relationship of cognitive function and the acquisition of coping skills in computer assisted treatment for substance use disorders. Drug and Alcohol Dependence 114:169-176. DOI: 10.1016/j.drugalcdep.2010.09.019

Kirst M, Mecredy G, Borland T, Chaiton M. 2014. Predictors of substance use among young adults transitioning away from high school: A narrative review. Substance Use and Misuse, 49:1795-1807. DOI: 10.3109/10826084.2014.933240

Kunert HJ, Derichs G, Irle E. 1996. Entwicklung von Aufmerksamkeitsfunktionen im Kindesalter: Ergebnisse einer vorläufigen Normierung der computergestützten Testbatterie zur Aufmerksamkeitsprüfung (TAP) an 9- bis 12jährigen Kindern. Zeitschrift Neuropsychology 7:92-113.

Lambe EK, Krimer LS, Goldman-Rakic PS. 2000. Differential postnatal development of catecholamine and serotonin inputs to identified neurons in prefrontal cortex of rhesus monkey. Journal of Neuroscience 20:8780-8787.

Lazarus RH, Folkman S. 1984. Stress, Appraisal and Coping. New York: Springer Publishing Company.

Marquez-Arrico JE, Benaiges I, Adan A. 2015. Strategies to cope with treatment in substance use disorder male patients with and without schizophrenia. Psychiatry Research 228:752759. DOI: 10.1016/j.psychres.2015.05.028

Mauro PM, Canham SL, Martins SS, Spira AP. 2015. Substance-use coping and self-rated health among US middle-aged and older adults. Addictive Behavior 42:96-100. DOI: 10.1016/j.addbeh.2014.10.031

Nyamathi A, Hudson A, Greengold B, Slagle A, Marfisee M, Khalilifard F, Patton R. 2010. Predictors of substance use severity among homeless youth. Journal of Child and Adolescent Psychiatric Nursing 23:214-222. DOI: 10.1016/j.addbeh.2009.04.002

Pechtel P, Woodman A, Lyons-Ruth K. 2012. Early maternal withdrawal and nonverbal childhood IQ as precursors for substance use disorder in young adulthood: Results of a 20-year prospective study. International Journal of Cognitive Therapy 5:316-329. DOI: 10.1521/ijct.2012.5.3.316

Pope HG, Gruber AJ, Hudson JI, Cohane G, Huestis MA, Yurgelun-Todd D. 2003. Early-onset cannabis use and cognitive deficits: What is the nature of the association? Drug and Alcohol Dependence 69:303-310. DOI: 10.1016/S0376-8716(02)00334-4

Shaw P, Greenstein D, Lerch J, Clasen L, Lenroot R, Gogtay N, Evans A, Rapoport J, Giedd J. 2006. Intellectual ability and cortical development in children and adolescents. Nature 440:676-679. DOI: 10.1038/nature04513

Skinner EA.1992. The Drug Abuse Screening Test. Addictive Behaviors 7:363-371. DOI: 10.1016/0306-4603(82)90005-3

Skinner EA, Edge K, Altman J, Sherwood H. 2003. Searching for the structure of coping: A review and critique of category systems for classifying ways of coping. Psychological Bulletin 129:216-269. DOI: 10.1037/0033-2909.129.2.216 
568

569

570

571

572

573

574

575

576

577

578

579

580

581

582

583

584

585

586

587

588

589

590

591

592

593

594

595

596
Suijkerbuijk AWM, Van Gils PF, Greeven PGJ, De Wit GA. 2015. De kosteneffectiviteit van interventies gericht op verslaving aan alcohol en drugs. Tijdschr Voor Psychiatrie 57:498-507.

Sundram S. 2006. Cannabis and neurodevelopment: Implications for psychiatric disorders. Human Psychopharmacology 21:245-254. DOI: 10.1002/hup.762

Tobin DL, Holroyd KA, Reynolds RV, Wigal JK. 1989. The hierarchical factor structure of the coping strategies inventory. Cognitive Therapy and Research 13: 343-361. DOI: 10.1007/BF01173478

United Nations Office on Drugs and Crime. 2015. World Drug Report. Available at https://www.unodc.org/documents/wdr2015/World_Drug_Report_2015.pdf/ (accessed 15 January 2017)

Walker R, Stephens R. 2014. Protective behavioral strategies mediate problem focused coping and alcohol use in college students. Addictive Behaviors, 39, 1003-1037. DOI: 10.1016/j.addbeh.2014.02.006

Wilson W, Mathew R, Turkington T, Hawk T, Coleman RE, Provenzale J. 2000. Brain morphological changes and early marijuana use: A magnetic resonance and positron emission tomography study. Journal of Addictive Diseases 19:1-22. DOI: 10.1300/J069v19n01_01

Witkiewitz K, Marlatt GA. 2004. Relapse prevention for alcohol and drug problems: That was Zen, this is Tao. American Psychologist 59:224-235. DOI: 10.1037/0003-066X.59.4.224

Woodcock EA, Lundahl LH, Stoltman JJK. 2015. Greenwald M. K. Progression to regular heroin use: Examination of patterns, predictors, and consequences. Addictive Behaviors 42:96-100. DOI: 10.1016/j.addbeh.2015.02.014

Woodhead E, Cronkite RC, Moos RH, Timko C. 2014. Coping strategies predictive of adverse outcomes among community adults. Journal of Clinical Psychology, 70, 1183-1195. DOI: $10.1002 /$ jclp. 21924

World Medical Association. 2013. WMA declaration of Helsinki: Ethical principles for medical research involving human subjects. Available at http://www.wma.net/en/30publications/10policies/b3/ (accessed 15 January 2017) 


\section{Table $\mathbf{1}$ (on next page)}

Descriptive statistics

Descriptive statistics (frequencies or mean and standard error) of the sociodemographic and clinical data, for the total sample and groups. 
1 Descriptive statistics (frequencies or mean and standard error) of the sociodemographic and clinical data, for the 2 total sample and groups, and the statistical contrasts carried out.

\begin{tabular}{|c|c|c|c|c|}
\hline & $\begin{array}{l}\text { Total sample } \\
(N=122)\end{array}$ & $\begin{array}{l}\text { OSU } \leq 16 \\
(N=60)\end{array}$ & $\begin{array}{l}\mathrm{OSU} \geq 17 \\
(N=62)\end{array}$ & $\begin{array}{l}\text { Statistical } \\
\text { contrasts }\end{array}$ \\
\hline \multicolumn{5}{|l|}{ Sociodemographic data } \\
\hline Age $(y r)$ & $35.97(0.75)$ & $33.60(1.09)$ & $38.25(0.96)$ & $U=1159.50^{* * *}$ \\
\hline Years of education & $10.36(0.23)$ & $10.25(0.33)$ & $10.48(0.32)$ & $t_{(120)}=-0.476$ \\
\hline Marital status & & & & $X_{(1)}^{2}=5.015$ \\
\hline Single & $51.6 \%$ & $51.7 \%$ & $51.6 \%$ & \\
\hline Separate/Divorced & $22.1 \%$ & $21.6 \%$ & $22.5 \%$ & \\
\hline Married & $14.8 \%$ & $13.3 \%$ & $16.1 \%$ & \\
\hline Stable partner & $11.5 \%$ & $13.3 \%$ & $9.7 \%$ & \\
\hline Economic status & & & & $X_{(1)}^{2}=4.305$ \\
\hline Unemployed & $29.5 \%$ & $30 \%$ & $29 \%$ & \\
\hline Active & $23.8 \%$ & $16.7 \%$ & $30.6 \%$ & \\
\hline No income & $19.7 \%$ & $23.3 \%$ & $16.1 \%$ & \\
\hline Disability pension & $16.4 \%$ & $20 \%$ & $12.9 \%$ & \\
\hline Sick leave & $10.7 \%$ & $10 \%$ & $11.3 \%$ & \\
\hline \multicolumn{5}{|l|}{ Clinical data } \\
\hline Relatives with SUD & $26.2 \%$ & $25 \%$ & $9.7 \%$ & $X^{2}{ }_{(1)}=5.024^{*}$ \\
\hline Relatives with others psychiatric disorder & $26.1 \%$ & $23.3 \%$ & $29 \%$ & $X_{(1)}^{2}=0.512$ \\
\hline Number of suicidal attempts & $0.23(0.66)$ & $0.30(0.10)$ & $0.16(0.06)$ & $t_{(120)}=1.144$ \\
\hline
\end{tabular}




\section{Table 2(on next page)}

Descriptive statistics of the data related to SUD

Descriptive statistics (frequencies or mean and standard error) of the data related to SUD, for the total sample and groups. 
Descriptive statistics (frequencies or mean and standard error) of the data related to SUD, for the total sample and groups, and the statistical contrasts carried out.

\begin{tabular}{|c|c|c|c|c|}
\hline SUD clinical characteristics & $\begin{array}{l}\text { Total sample } \\
(N=122)\end{array}$ & $\begin{array}{l}\text { OSU } \leq 16 \\
(N=60)\end{array}$ & $\begin{array}{l}\text { OSU } \geq 17 \\
(N=62)\end{array}$ & $\begin{array}{l}\text { Statistical } \\
\text { contrasts }\end{array}$ \\
\hline \multicolumn{5}{|l|}{ Consumption pattern } \\
\hline One substance & $23.8 \%$ & $18.3 \%$ & $29 \%$ & $U=1661$ \\
\hline Two substances & $34.4 \%$ & $30 \%$ & $38.7 \%$ & $U=1698$ \\
\hline Polydrug use & $41.8 \%$ & $51.7 \%$ & $32.3 \%$ & $U=1499^{*}$ \\
\hline \multicolumn{5}{|l|}{ Substances used ${ }^{\mathrm{a}}$} \\
\hline Cocaine & $87.7 \%$ & $81.7 \%$ & $93.5 \%$ & $X_{(1)}^{2}=3.992^{*}$ \\
\hline Alcohol & $72.1 \%$ & $76.7 \%$ & $67.7 \%$ & $X^{2}(1)=1.208$ \\
\hline Cannabis & $43.4 \%$ & $60 \%$ & $27.4 \%$ & $X_{(1)}^{2}=13.173^{* * *}$ \\
\hline Hallucinogens & $16.4 \%$ & $23.3 \%$ & $9.7 \%$ & $X_{(1)}^{2}=4.149^{*}$ \\
\hline Opioids & $14.8 \%$ & $16.7 \%$ & $12.9 \%$ & $X^{2}(1)=0.343$ \\
\hline Sedatives & $4.1 \%$ & $5 \%$ & $3.2 \%$ & $X_{(1)}^{2}=0.244$ \\
\hline Age of OSU (yr) & $19.16(0.59)$ & $14.98(0.15)$ & $23.20(0.88)$ & $U=17.50^{* * *}$ \\
\hline Duration of drug use (yr) & $16.13(0.77)$ & $17.98(1.07)$ & $14.33(1.06)$ & $t_{(120)}=2.432^{*}$ \\
\hline Typology of treatment regimen & & & & $X_{(1)}^{2}=6.124^{*}$ \\
\hline Residential & $62.3 \%$ & $73.3 \%$ & $51.6 \%$ & \\
\hline Ambulatory & $37.7 \%$ & $26.7 \%$ & $48.4 \%$ & \\
\hline Daily number of medication & $0.51(0.08)$ & $0.65(0.14)$ & $0.36(0.08)$ & $t_{(120)}=1.813$ \\
\hline Months of abstinence & $8.14(0.47)$ & $7.60(0.59)$ & $8.66(0.72)$ & $t_{(120)}=-1.127$ \\
\hline Past treatment for SUD & & & & $X_{(1)}^{2}=0.085$ \\
\hline Yes & $50.5 \%$ & $51.9 \%$ & $48.9 \%$ & \\
\hline \multicolumn{5}{|l|}{ Number of relapses } \\
\hline None & $57 \%$ & $56.7 \%$ & $57.4 \%$ & $U=1856$ \\
\hline One & $16.5 \%$ & $13.3 \%$ & $19.7 \%$ & $U=1718$ \\
\hline Two & $10.7 \%$ & $15 \%$ & $6.6 \%$ & $U=1701$ \\
\hline Three or more & $15.7 \%$ & $15 \%$ & $16.4 \%$ & $U=1825.50$ \\
\hline Drug Abuse Screening Test (DAST-20) & $12.15(0.47)$ & $12.33(0.57)$ & $11.94(0.78)$ & $t_{(1)}=0.418$ \\
\hline Clinical Global Impression (CGI) & $2.45(0.11)$ & $2.58(0.17)$ & $2.33(0.15)$ & $t_{(1)}=1.069$ \\
\hline
\end{tabular}

Clinical Global Impression (CGI)

Notes.

SUD: Substance Use Disorder; OSU $\leq 16$ : Onset of substance use at age 16 or earlier; OSU $\geq 17$ : Onset of substance use at age 17 or later; OSU: Onset of substance use; yr: years; DAST-20: Drug Abuse Screening Test; CGI: Clinical Global Impression. 
51 a Percentages will not equal 100 as each participant may take more than one substance of abuse.

$52 * \mathrm{p}<.05 ; * * * \mathrm{p}<.001$ 


\section{Table 3 (on next page)}

Means and standard deviations for the Coping Strategies Inventory (CSI).

Means and standard deviations for the total sample and for each group for the Coping Strategies Inventory (CSI). 
Means and standard deviations for the total sample and for each group, and results of the MANCOVA analyses for both groups considering age as a covariate for the Coping Strategies Inventory (CSI).

\begin{tabular}{|c|c|c|c|c|c|}
\hline CSI & $\begin{array}{l}\text { Total sample } \\
(N=122)\end{array}$ & $\begin{array}{l}\text { OSU } \leq 16 \\
(n=60)\end{array}$ & $\begin{array}{l}\text { OSU } \geq 17 \\
(n=62)\end{array}$ & $F$ & $\begin{array}{l}\text { Effect } \\
\text { size }\end{array}$ \\
\hline \multicolumn{6}{|l|}{ Primary subscales } \\
\hline Problem Solving & $13.31(4.76)$ & $12.83(4.69)$ & $13.77(4.82)$ & 0.835 & 0.007 \\
\hline Cognitive Restructuring & $10.44(5.04)$ & $9.72(5.05)$ & $11.16(4.97)$ & 2.705 & 0.022 \\
\hline Social Support & $11.50(5.03)$ & $10.50(5.35)$ & $12.48(4.52)$ & $5.628^{*}$ & 0.045 \\
\hline Express Emotions & $10.37(5.08)$ & $10.70(5.25)$ & $10.05(4.94)$ & 0.891 & 0.007 \\
\hline Problem Avoidance & $5.77(4.64)$ & $6.85(5.32)$ & $4.76(3.63)$ & $4.471^{*}$ & 0.036 \\
\hline Wishful Thinking & $14.69(4.81)$ & $14.60(4.67)$ & $14.77(4.99)$ & 0.004 & 0.001 \\
\hline Social Withdrawal & $9.68(5.30)$ & $10.77(5.18)$ & $8.63(5.25)$ & $3.959^{*}$ & 0.029 \\
\hline Self-Criticism & $13.57(5.09)$ & $13.48(5.29)$ & $13.66(4.95)$ & 0.081 & 0.011 \\
\hline Self-Perceived Capacity & $2.70(1.33)$ & $2.50(1.42)$ & $2.90(1.21)$ & 1.245 & 0.010 \\
\hline \multicolumn{6}{|l|}{ Secondary subscales } \\
\hline Problem Focused Engagement & $23.78(8.08)$ & $22.60(8.29)$ & $24.91(7.77)$ & 2.353 & 0.019 \\
\hline Emotion Focused Engagement & $21.79(8.10)$ & $21.10(8.71)$ & $22.45(7.48)$ & 0.772 & 0.006 \\
\hline Problem Focused Disengagement & $20.53(5.92)$ & $21.45(6.21)$ & $19.62(5.52)$ & 2.562 & 0.021 \\
\hline Emotion Focused Disengagement & $23.48(8.64)$ & $24.25(8.28)$ & $22.72(8.98)$ & 0.423 & 0.004 \\
\hline \multicolumn{6}{|l|}{ Tertiary subscales } \\
\hline Engagement & $45.59(14.26)$ & $43.70(14.98)$ & $47.42(13.39)$ & 1.944 & 0.016 \\
\hline Disengagement & $43.61(10.92)$ & $45.87(11.16)$ & $41.44(10.31)$ & $4.417^{*}$ & 0.036 \\
\hline
\end{tabular}

Notes.

OSU $\leq 16$ : Onset of substance use at age 16 or earlier; $O S U \geq 17$ : Onset of substance use at age 17 or later. $* \mathrm{p}<.05$. 


\section{Table 4 (on next page)}

Multiple linear regression for the Coping Estrategies

Multiple linear regression for the Coping Strategies Inventory (CSI) considering as independent variables the sociodemographic and clinical data that showed significant correlations, for the total sample $(N=122)$ and for the OSU $\leq 16(N=60)$ and OSU $\geq 17(N=$ 62) groups. 
Multiple linear regression for the Coping Strategies Inventory (CSI) considering as independent variables the sociodemographic and clinical data that showed significant correlations, for the total sample $(N=122)$ and for the $\mathrm{OSU} \leq 16(N=60)$ and $\mathrm{OSU} \geq 17(N=62)$ groups.

\begin{tabular}{|c|c|c|c|c|c|}
\hline CSI & Adjusted $R^{2}$ & $F$ & $I V^{\mathrm{a}}$ & $\beta$ Standardized & $p$ values \\
\hline \multicolumn{6}{|l|}{ Total Sample } \\
\hline Wishful Thinking & 0.167 & $15.279^{* * *}$ & DAST-20 & 0.423 & .0001 \\
\hline Social Withdrawal & 0.133 & $11.900^{* *}$ & DAST-20 & 0.381 & .001 \\
\hline Problem Focused Disengagement & 0.113 & $10.022^{* *}$ & DAST-20 & 0.166 & .002 \\
\hline Emotion Focused Disengagement & 0.232 & $8.157^{* * *}$ & $\begin{array}{l}\text { Age of OSU }(\mathrm{yr}) \\
\text { Number of relapses } \\
\text { DAST-20 }\end{array}$ & $\begin{array}{r}-0.276 \\
0.220 \\
0.302\end{array}$ & $\begin{array}{l}.010 \\
.047 \\
.007\end{array}$ \\
\hline Disengagement & 0.146 & $7.072^{* *}$ & $\begin{array}{l}\text { Age of OSU }(y r) \\
\text { Number of relapses }\end{array}$ & $\begin{array}{r}-0.269 \\
0.300\end{array}$ & $\begin{array}{l}.017 \\
.008\end{array}$ \\
\hline \multicolumn{6}{|l|}{ OSU $\leq 16$} \\
\hline Wishful Thinking & 0.187 & $9.732^{* *}$ & DAST-20 & 0.456 & .003 \\
\hline Social Withdrawal & 0.265 & $7.835^{* *}$ & $\begin{array}{l}\text { Number of relapses } \\
\text { DAST-20 }\end{array}$ & $\begin{array}{l}0.322 \\
0.387\end{array}$ & $\begin{array}{l}.029 \\
.010\end{array}$ \\
\hline $\begin{array}{l}\text { Problem Focused Disengagement } \\
\text { Emotion Focused Disengagement }\end{array}$ & 0.218 & $6.307^{* *}$ & $\begin{array}{l}\text { Number of relapses } \\
\text { DAST-20 }\end{array}$ & $\begin{array}{l}0.315 \\
0.342\end{array}$ & $\begin{array}{l}.038 \\
.025\end{array}$ \\
\hline Disengagement & 0.120 & $6.159^{*}$ & Number of relapses & 0.378 & .018 \\
\hline \multicolumn{6}{|l|}{ OSU $\geq 17$} \\
\hline Wishful Thinking & 0.131 & $5.827^{*}$ & DAST-20 & 0.398 & .022 \\
\hline Social Withdrawal & 0.105 & $4.740^{*}$ & DAST-20 & 0.364 & .037 \\
\hline Problem Focused Disengagement & 0.171 & $7.577^{*}$ & DAST-20 & 0.443 & .010 \\
\hline $\begin{array}{l}\text { Emotion Focused Disengagement } \\
\text { Disengagement }^{\mathrm{b}}\end{array}$ & 0.115 & $5.138^{*}$ & DAST-20 & 0.377 & .031 \\
\hline
\end{tabular}

Notes.

OSU $\leq 16$ : Onset of substance use at age 16 or earlier; OSU $\geq 17$ : Onset of substance use at age 17 or later; IV: Independent Variables; DAST-20: Drug Abuse Screening Test; OSU: Onset of Substance Use; yr: years.

a Only significant variables are presented that comprise each explicative model. In all cases, the Tolerance values were higher than 0.91 and the Variance Inflation Factor values lower than 1.09 ; b Any explicative model was significant.

$* \mathrm{p}<.05 ; * * \mathrm{p}<.01 ; * * \mathrm{p}<.001$. 
Figure 1

Mean of percentile scores for the Coping Strategies Inventory

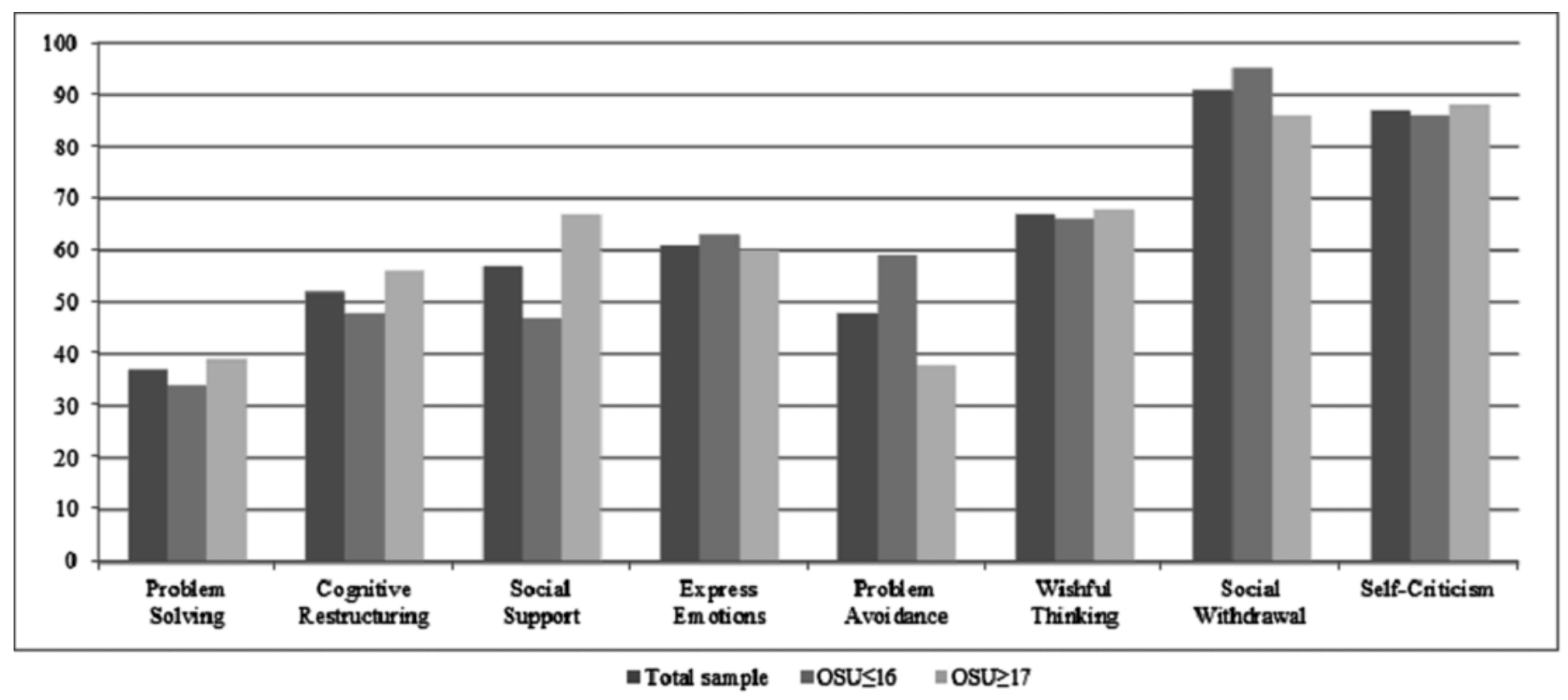

